\title{
RỐI LOẠN NHỊP TIM Ở BỆNH NHÂN CÓ HộI CHÚNG NGƯNG THỞ KHI NGỦ TĂC NGHẼN
}

Nguyễn Tá Đông

Trung tâm tim mạch - Bệnh viện Trung ương Huế

\section{ABSTRACT \\ Arrhythmias in the patients with obstructive sleep apnea syndrom}

Obstructive sleep apnea Syndrom (OSAS):

The disease is quite common but often overlooked and less interested in. The disease is caused by many causes that can be alone or in combination. Diagnosis of the disease is not too difficult but if untreated it can cause serious complications, especially cardiovascular complications that one of them, arrhythmias play a major role in causing death and cardiovascular events in OSAS patients. The treatment of arrhythmias in OSAS patients must first address the causes of OSAS and then treat arrhythmias according to the appropriate guidelines.

\section{TÓM TẮT}

Hội chứng ngưng thở khi ngủ tắc nghẽn (OSAS) là bệnh lý có tần suất mắc bệnh khá phổ biến nhưng thường bị bỏ qua và ít được quan tâm. Bệnh do nhiều nguyên nhân gây nên có thể đơn độc hay phối hợp. Chẩn đoán bệnh không phải là quá khó nhưng nếu không được điều trị bệnh có thể gây nên các biến chứng nghiêm trọng, đặc biệt là các biến chứng trên tim mạch mà rối loạn nhịp tim có vai trò chủ yếu trong việc gây tử vong và biến cố tim mạch ở bệnh nhân OSAS. Việc điều trị rối loạn nhịp tim ở bệnh nhân OSAS trước hết phải giải quyết các nguyên nhân gây OSAS sau đó mới điều trị rối loạn nhịp tim theo các hướng dẫn phù hợp.

Chịu trách nhiệm chính: Nguyễn Tá Đông

Ngày nhận bài: 15/11/2019

Ngày phản biện khoa học: 20/12/2019

Ngày duyệt bài: 31/12/2019

\section{KHÁI NIỆM:}

\subsection{Các thuật ngữ thường dùng:}

- Rối loạn nhịp thở khi ngủ (Sleep - disordered breathing: SDB) các bất thường về tần số và / hoặc biên độ hô hấp trong khi ngủ.

- Hội chứng ngưng thở khi ngủ (sleep apnea syndrome - SAS): Trong khi ngủ có lúc ngưng thở $\geq 10$ giây.

- OSAS (Obstructive sleep apnea syndrom ): Hội chứng ngưng thở khi ngủtắt nghẽn là loại ngưng thở khi ngủ phổ biến nhất và gây ra bởi các vật cản hoàn toàn hoặc một phần của đường hô hấp trên và OSAHS (Obstructive sleep apnea - hypopnea syndrom ): Hội chứng suy hô hấp ngưng thở khi ngủ tắt nghẽn.

- Hội chứng giảm thông khí do béo phì (obesity hypoventilation syndrome).

- Ngưng thở khi ngủ trung ương (central sleep apnea):

- Ngưng thở tái đi tái lại khi ngủ + không có gắng sức cơ hô hấp..

- Kết hợp với bệnh TK.

- Hội chứng tăng sức cản đường thở trên upper-airway resistance syndrome.

- Ngưng thở hổn hợp: Bắt đầu trung ương $\rightarrow$ tắc nghẽn/ cùng chu kỳ. Đa số OSAS có cả dạng tắc nghẽn và hỗn hợp.

- Thở kiểu Cheyne-Stokes: Có khoảng ngưng thở rồi thở tăng dần cả biên độ, cả tần số đến tối đa rồi giảm dần cũng cả biên độ và tần số rồi ngưng thở trở lại, chu kỳ cứ lập lại như vậy.

1.2. Dịch tể học: Đây là bệnh lý có tần suất mắc bệnh khá phổ biến (44\% ở nam và $28 \%$ ở nữ) mà hầu như thường được bỏ qua và ít được mọi người quan tâm [3]. Ở Mỹ nếu tính $\mathrm{AHI}>5 / \mathrm{hr}$ thì có $24 \%$ ở Nam và $9 \%$ ở Nữ mắc bệnh. Nếu $\mathrm{AHI}>5 / \mathrm{hr}$ có kèm triệu chứng vào ban ngày thì có $4 \%$ ở nam và $2 \%$ ở nữ mắc bệnh. Ở Thailand nếu chỉ tính $\mathrm{AHI}>5 / \mathrm{hr}$ thì có $15.8 \%$ ở Nam và $6.3 \%$ ở Nữ mắc bệnh và nếu $A H I>5 / h r$ và có kèm triệu chứng thì chỉ $4.8 \%$ ở Nam và $1.9 \%$ ở Nữ bị mắc bệnh lý này [3],[4]. Theo 
Puvanendran K, Goh GL ở Singapore khoảng $15 \%$ dân số mắc bệnh OSAS và $24.09 \%$ người có thói quen thường xuyên ngủ ngáy to[5]. Còn ở Mallaysia thì khoảng 44.3\% có OSA • $28.7 \%$ OSA nhẹ ; 9\% OSA trung bình và $6.6 \%$ OSA nặng [6]...

\section{CHẨN ĐOÁN HỘI CHỨNG NGUNGG THỞ KHI NGÜ:}

Chẩn đoán OSAS: Khi bệnh nhân có $\mathrm{A}$ và/ hoặc B + C

A. Những triệu chứng ngủ nhiều ban ngày không giải thích được: (đánh giá qua thang điểm ngủ Epworth: $>10$ điểm)

B. Có $\geq 2$ triệu chứng như:

- Khó thở hay thở hổn hển khi ngủ,

- Thức đêm nhiều lần, không ngủ lại được,

- Mệt mỏi ban ngày, giảm khả năng tập trung.

C. Qua đa miên ký (polysomnographic) giấc ngủ hay hô hấp. Xác định:

Chỉ số ngưng, giảm thở ( apnea/ hypopnea index- AHI): Trung bình số lần ngưng thở và giảm thở / 1 giờ ngủ: $\geq 5$ lần/giờ

Chỉ số rối loạn hô hấp (respiratory disturbance index- RDI): Trung bình số lần ngưng thở, giảm thở và tỉnh giấc do sự cố hô hấp /1 giờ ngủ: $R D I \geq 15$ lần/ giờ

\section{NGUYÊN NHÂN VÀ CÁC YTNC CỦA HC NGƯNG THỞ KHI NGỦ TẮC NGHẼN:}

3.1. Nguyên nhân: Hầu hết các trường hợp OSAS được cho là do:

- Tuổi già (tự nhiên hoặc sớm) viễn)

- Chấn thương não (tạm thời hoặc vĩnh

- Giảm trương lực cơ. Điều này có thể do thuốc hoặc rượu gây ra, hoặc nó có thể do các vấn đề về thần kinh hoặc các rối loạn khác gây ra. Cũng có một giả thuyết cho rằng chứng ngáy dài hạn có thể gây tổn thương dây thần kinh cục bộ trong họng hầu như cách tiếp xúc lâu dài với rung có thể gây tổn thương dây thần kinh ở các bộ phận khác của cơ thể. Ngáy là một rung động của các mô mềm của đường hô hấp trên, và các nghiên cứu đã cho thấy các phát hiện điện sinh lý trong các dây thần kinh và cơ của thanh quản cho thấy tổn thương thần kinh địa phương.

tăng mô mềm xung quanh đường thở (đôi khi do béo phì), vàcác tính năng cấu trúc làm phát sinh một đường khí thu hẹp.

- Béo phì: Người lớn béo phì cho thấy sự gia tăng trong mô hầu họng gây tắc nghẽn đường hô hấp trong khi ngủ. Người lớn có chỉ số khối cơ thể (BMI) tăng thường bị giảm trương lực cơ gây sụp đường thở và tạo ra hiện tượng ngưng thở khi ngủ. Ngủ ở tư thế nằm ngửa cũng là một yếu tố nguy cơ đối với OSA. Vị trí ngủ nằm ngửa tạo ra việc kéoxương hàm dưới và đáy lưỡi xuốngtạo cơ sở giải phẫu cho tắc nghẽn đường hô hấp trong khi ngủ.

\subsection{Yếu tố nguy cơ}

+ Tuổi già thường đi kèm với tổn thương cơ bắp và thần kinh của các cơ dọc đường hô hấp trên. Yếu cơ cũng có thể là tạm thời gây ra bởi sự trầm cảm; đồ uống có cồn và thuốc an thần là loại thuốc phổ biến nhất gây chứng yếu cơ.

+ Chứng thất ngôn vận động sớm vĩnh viễn ở đường hô hấp trên có thể là kết quả gây ra bởi chấn thương sọ não, rối loạn thần kinh cơ, hoặc tuân thủ kém các phương pháp điều trị hóa học và liệu pháp ngôn ngữ.

+ Cá nhân bị giảm trương lực cơ và tăng mô mềm xung quanh đường hô hấp, và các đặc điểm cấu trúc gây ra đường hô hấp bị thu hẹp có nguy cơ cao đối với OSAS.

+ Giới tính: Đàn ông, trong đó giải phẫu được xác định bởi khối lượng gia tăng ở thân và cổ, có nguy cơ cao bị phát triển chứng ngưng thở khi ngủ, đặc biệt là qua tuổi trung niên và sau đó. Phụ nữ ít bị thường xuyên hơn và ở mức độ thấp hơn nam giới, một phần là do sinh lý học, nhưng cũng có thể ở mức độ khác nhau của nồng độ progesteronetrong máu. Tỷ lệ phụ nữ bị OSAS sau tuổi mãn kinh gần bằng với nam giới ở cùng độ tuổi. Phụ nữ có nhiều nguy cơ phát triển OSAS hơn trong thai kỳ[8].

+ OSAS dường như cũng có một phần liên quan đến di truyền; những người có tiền sử gia đình bị OSAS có nhiều khả năng tự phát sinh OSAS. Một số nghiên cứu đã chỉ ra rằng 
bệnh sử của gia đình có nhiều người mắc chứng ngưng thở khi ngủ cũng làm tăng nguy cơ OSAS 2-4 lần [7].

+ Các yếu tố lối sống như hút thuốc cũng có thể làm tăng nguy cơ phát triển OSAS, khi các chất kích thích hóa học trong khói có xu hướng làm sưng nề mô mềm của đường hô hấp trên và thúc đẩy việc giữ nước, cả hai đều có thể dẫn đến thu hẹp đường hô hấp trên. Một người cũng có thể trải nghiệm hoặc làm trầm trọng thêm $\mathrm{OSAS}$ với việc sử dụng rượu, thuốc an thần hoặc bất kỳ loại thuốc nào khác làm tăng buồn ngủ vì hầu hết các loại thuốc này cũng là thuốc giãn cơ[6].

\section{RỐI LOẠN NHỊP TIM Ở BỆNH NHÂN OSAS:}

\subsection{Cơ chế rối loạn nhịp tim ở bệnh nhân OSAS:}

+ Cơ chế rối loạn nhịp tim ở bệnh nhân OSAS liên quan đến rất nhiều yếu tố, một lượng lớn cathecholamin được phóng thích lúc ngủ có ngưng thở đóng vai trò quan trọng trong cơ chế này.

+ Sự giảm độ bão hòa oxy máu động mạch cũng là một mối quan tâm trong vấn đề RLNT.

+ Trong trường hợp nặng và kéo dài, tăng áp lực động mạch phồi được dẫn đến tăng áp lực buồng tim phải. Điều này có thể dẫn đến một dạng suy tim sung huyết thường được gọi là tâm phế mạn. Chức năng tâm trương của tim cũng bi ảnh hưởng[6]. Âp lực động mạch cao (tăng huyết áp ) có thể là hậu quả của hội chứng OSAS [7]. Khi tăng huyết áp do OSAS gây ra, không giống như hầu hết các trường hợp THA thông thường bởi chúng được gọi là tăng huyết áp cần thiết.

+ Ngoài ra thì một số yếu tố khác như thần kinh thực vật bị rối loạn, yếu tố tâm lý, dễ kích thích bởi yếu tố ngoại lai... cũng góp phần làm tăng tỷ lệbị RLNT ở bệnh nhân OSAS.

+ Các RLNT thường xảy ra trong giai đoạn ngủ REM (rapid eye movement) là giai đoạn chuyển động mắt nhanh, đây là giai đoạn ngủ sâu của bệnh nhân. Trong giai đoạn này, bệnh nhân thường bị hiện tượng tắt nghẽn ở vùng hầu họng nặng nhất và chính điều này gây cản trở dòng khí lưu thông ra vào phổi dẫn đến thiếu khí và giảm độ bảo hòa oxy máu, là nguồn gốc của hàng loạt các rối loạn bất thường xảy ra và là chuổi vòng luẩn quẩn: bệnh tim mạch và hội chứng ngưng thở khi ngủ.

\subsection{Rối loạn nhịp tim là vấn đề thường gặp ở bệnh nhân OSAS: \\ + Sự hiện diện và tính phức tạp của các} RLN nhanh, RLN chậm có thể ảnh hưởng đến tỷ lệ mắc bệnh, tỷ lệ tử vong, và chất lượng sống của bệnh nhân OSAS.

+ Các RLNT thường gặp ở bệnh nhân ngưng thở khi ngủ là: nhịp nhanh thất không bền bỉ, ngưng xoang, block nhĩ thất cấp II và NTT thất cặp đôi, cặp ba...

+ RLNT nhanh khác như: NNKP trên thất bền bỉ,rung nhĩ, cuồng nhĩ, RLN thất đặc biệt là nhịp nhanh thất bền bỉ hay không bền bỉ thường xảy ra trên bệnh nhân OSAS có bệnh tim cấu trúc sẵn.

+ RLNT thường gặp, xảy ra với tỷ lệ cao > 50 \% ở bệnh nhân OSAS.

+ Vai trò điều trị OSAS làm cải thiện các biểu hiện triệu chứng RLNT, điều này thể hiện khi nghiên cứu đánh giá sự tái phát ở những bệnh nhân OSAS bị rung nhĩ được chuyển nhịp xoang, có $82 \%$ trường hợp bị tái phát rung nhĩ sau 12 tháng nếu không điều trị với thở áp lực dương liên tục: CPAP (continuose positive air pressure) với chỉ 42 \% bệnh nhân bị tái phát ở nhóm được điều trị CPAP. Có thể kết luận việc điều trị CPAP đối với OSAS sẽ làm giảm khả năng bị RLNT.

+ Đặc biệt, các RLNT chậm như ngưng xoang, block $\mathrm{A}-\mathrm{V}$ hay vô tâm thu... thường có thể xảy ra trong giai đoạn ngủ REM và ngay cả trên bệnh nhân không có sẵn các biểu hiện của rối loạn dẫn truyền trong tim. Từ đó đặt ra vấn đề: Máy tạo nhịp tim vĩnh viễn có thể là giải pháp điều trị hữu hiệu cho bệnh nhân OSAS có RLN chậm hay không? Có thể cải thiện được cácbiến chứng tim mạch nhưng không cải thiện được bệnh lý OSAS.

+ Cụ thể qua một số nghiên cứu đánh giá các RLNT bằng Holter điện tim 24 giờ trên bệnh nhân OSAS. Guilleminault và cộng sự 
nghiên cứu trên 400 bệnh nhân OSAS nhận thấy có rối loạn nhịp chậm chiếm $18 \%$ bệnh nhân, NNKP thất bền bỉ chiếm $2 \%$; Ngưng xoang chiếm $11 \%$; block nhĩ thất cấp II chiếm $8 \%$; NTT thất chiếm $19 \%$ bệnh nhân.

Flemons và cộng sự nghiên cứu trên 263 bệnh nhân OSAS ghi nhận NTT thất phức tạp kể cả NNKP thất chiếm $1,3 \%$ bệnh nhân; Tỷ lệ NTT thất dày $(>30 / \mathrm{h})$ là $2,6 \%$; Block $\mathrm{A}-\mathrm{V}$ cấp II chiếm 1,3\%; Ngưng xoang 5,2 \% bệnh nhân.

Theo Becker và cộng sự khi nghiên cứu trên 239 bệnh nhân OSAS phát hiện ngưng xoang và Block $\mathrm{A}-\mathrm{V}$ chiếm $30 \%$ bệnh nhân còn Mooe và cộng sự thì ghi nhận rung nhĩ chiếm $32 \%$ bn có $(A H I) \geq 5$ và chỉ $18 \%$ bệnh nhân OSAS có chỉ số $\mathrm{AHI}<5$ và tỷ lệ rung nhĩ xảy ra $39 \%$ bệnh nhân có chỉ số bảo hòa oxy $(\mathrm{ODI}) \geq 5$ và chỉ có $18 \%$ bệnh nhân có chỉ số này $<5$.

Một nghiên cứu khác của Javaheri và cộng sự ghi nhận trên 81 bệnh nhân OSAS tỷ lệ rung nhĩ chiếm $32 \%$ bệnh nhân. Mehra và cộng sự nghiên cứu trên 566 bệnh nhân OSAS ghi nhận tỷ lệ 4,8 \% bệnh nhân rung nhĩ, $5,3 \%$ nhịp nnhanh thất không bền bỉ và $25 \%$ bệnh nhân NTT thất phức tạp.

\section{5. ĐIỀU TRI RỐI LOẠN NHỊP TIM TRONG HỘI CHÚNG NGƯNG THỞ KHI NGÜ:}

+ Đầu tiên cần phải điều chỉnh, kiểm soát tình trạng tắc nghẽn đường thở, bao gồm việc thay đổi lối sống là quan trọng trong việc quản lý bệnh nhân bị OSAS.

+ Thay đổi lối sống bao gồm giảm cân, giảm lượng rượu, rút thuốc và thuốc an thần ảnh hưởng đến giai điệu đường thở, cai thuốc lá, tránh mất ngủ và điều chỉnh vị trí ngủ.

+ Điều trị OSAS bằng áp lực đường hô hấp dương liên tục (CPAP) là lựa chọn ưu tiên hàng đầu. Đó là một thiết bị thở khí nén áp lực dương dọc đường thở trên trong khi bệnh nhân đang ngủ. CPAP được chuẩn độ đến mức có thể giúp loại bỏ chứng ngáy, thường là dùng áp lực từ $5-20 \mathrm{~cm} \mathrm{Hg}$. Một số thuốc có thể sử dụng như fluoxetine, paroxetine, acetazolamide and tryptophan...

+ Các bệnh kèm theo khác như THA, ĐTĐ, béo phì, bệnh TMH, RHM... nên được xác định và điều trị đúng hướng dẫn điều trị.

+ Điều trị RLNT theo đúng hướng dẫn điều trị rối loạn nhịp tim của $\mathrm{AHA} / \mathrm{ACC} / \mathrm{HRS}$ 2017 [1].

\section{TÀI LIÊU THAM KHẢO}

1. AHA/ACC/HRS (2017): Guideline for Management of Patients With Ventricular Arrhythmias and the Prevention of Sudden Cardiac Death.

2. Young $\mathrm{T}$, et al. $\mathrm{N}$ Engl $\mathrm{J}$ Med. 1993;328(17):1230-5.

3. Young T, et al. Am J Resp Care Med 2002;165(9)1217-39.

4. Neruntarat C, et al. (2011): Sleep Breath;15(4):641-8.

5. Puvanendran K, Goh GL (1999): From snoring to sleep apnea in Singapore population - Sleep Res Online 2 (1); 11,4

6. Javaheri et al (2017): Obstructive sleep apneasyndrom and cardiovascular diseases - Circulation;126:1495-1510.

7. Mayoclinic.org/patient-care-and-healthinformation (2018): Obstructive sleep apnea- 20: 35 - 209

8. Himanshu Wickramasinghe (2019): Obstructive sleep apnea- Updated: Mar 22, 2019

9. Qaseem, A; Holty, JE; Owens, DK; Dallas, P; Starkey, M; Shekelle, P (Sep 24, 2013): "Management of Obstructive Sleep Apnea in Adults: A Clinical Practice Guideline From the American College of Physicians". Annals of Internal Medicine. 159 (7): 471-83. 